Vol. 5, No. 1, 2019

Yurii Sholovii ${ }^{1}$, Nadiia Maherus ${ }^{2}$

${ }^{1}$ Department of Mechanics and Automation Engineering, Lviv Polytechnic National University, Ukraine, Lviv, S. Bandery street 12, ORCID 0000-0003-0154-7983, E-mail: j-sholov@ukr.net

${ }^{2}$ Department of Mechanics and Automation Engineering, Lviv Polytechnic National University, Ukraine, Lviv, S. Bandery street 12, ORCID 0000-0003-1946-8503, E-mail: maherusn@gmail.com

\title{
SUBSTANTIATION OF GEOMETRIC PARAMETERS OF DISCHARGE HOPPER HOLE AT GRAVITATIONAL OUTFLOW OF FINELY DISPERSED BULKY MATERIAL
}

Received: February 14, 2019 / Revised: April 18, 2019 / Accepted: June 26, 2019

(C) Sholovii Yu., Maherus N., 2019

Abstract. The variability of physical and mechanical properties of finely dispersed bulky materials during processing and storage, the manner and height of filling the tanks; the terms and conditions of storage have a decisive influence on the choice of parameters of the discharge hoppers of bunkers with gravitational outflow. Therefore, the purpose of the article was to justify the geometric parameters of the discharge hopper to provide a gravitational outflow of finely dispersed bulky materials. The geometrical parameters of the discharge hoppers were determined through mathematical simulation of the flow outflow of materials under the influence of gravity forces and the analysis of the tense state of bulky materials in the zone of outflow. As a result of mathematical simulation, the maximum diameter of the outlet of the hopper hole is determined, that implements the effect of "self-locking" the flow of the product is realized. The influence of physical and mechanical characteristics of finely dispersed bulky materials and angles the conical discharge hopper hole on the size of the outlet during the gravitational outflow is established. The mathematical model of the gravitational outflow of materials with conical discharge hopper hole, which takes into account the complexity of the nature of physical and mechanical connections between particles of materials is developed in the article. The research results allow to design bunkers for storage of finely dispersed bulky materials, to predict their behaviour with gravitational outflow and to ensure reliable operation of bunkers during their unloading. Also, in the future, it is advisable to carry out mathematical simulation of the process of gravitational outflow of finely dispersed bulky materials from bunkers of various cross sections and with different forms of the discharge hoppers.

Keywords: finely dispersed bulky materials, gravitational outflow, discharge hopper hole, elementary volume of the dome, autohesion force, passive stress state.

\section{Introduction and Problem Statement}

The variability of physical and mechanical properties of finely dispersed bulky materials (BM) in processing and storage, the manner and height of filling the tanks; the terms and conditions of storage must be taken into account when designing the hoppers. The knowledge of the impact of these factors, as well as the structural parameters of the discharge hopper holes (the size and shape of the outlet, the angle of the walls, etc.), are decisive factors affecting the performance of the hopper discharge process. The chaotic and unpredictable movement of finely dispersed BM in the hopper, and sometimes its complete absence, due to significant clutch forces, causes sticking the product to the hopper walls and the discharge hole which negatively affects the outflow process [1].

Important design parameters that determine the performance of BM hoppers are the size and shape of the discharge hopper. Therefore, an important stage in their establishment is the study of the influence of 
physical and mechanical properties of fine-dispersed BM on the geometric parameters of the hopper hole, as well as the interaction between them.

\section{Review of Modern Information Sources on the Subject of the Paper}

Since the outflow of BM from the hoppers is characterized with a number of problems, so far there is no single hypothesis that would unambiguously describe the movement of BM during the discharge of hoppers. Platonov P. M., Pokrovsky G. I., Arefiev A. I., Linchevsky I. T. proposed a hypothesis of selfdischarging dome [11], the essence of which was that when the BM flows out of the outlet, a dynamic dome is formed, which collapses instantly. According to this hypothesis, the main parameter that affects the behaviour of BM is the size of the outlet. Zenkov R. L. and Alfiorov K. V. [5] put forward the theory that the behaviour of BM does not depend on the size of the outlet, but only on the height of the BM in the hopper. It was found that depending on the physical and mechanical properties of the BM, as well as the geometric sizes of the hopper, various forms of movement of material [9] appear, which are directly related to its the tense state. Numerous studies [12] have found that conditions of the outflow of BM in the conical discharge hopper hole are less favourable than on its cylindrical part.

Therefore, analysing various models that allow us to describe the movement of BM, we can conclude that, in view of the variability of the physical and mechanical characteristics of finely dispersed bulky materials, the most effective way to study its behaviour is to develop a mathematical model of the outflow of BM based on the model of a continuous medium.

\section{Objectives and Problems of Research}

The purpose of the research is to justify the geometric parameters of the hopper discharge hole to provide a gravitational outflow of finely dispersed bulky materials based on the results of the mathematical simulation of the process.

Problems of research: 1) to develop a mathematical model based on the analysis of the behaviour of finely dispersed BM in its gravitational outflow; 2) to establish analytical dependencies for determination of parameters of a hopper discharge hole; 3 ) to make simulation of the behaviour of finely dispersed bulky materials with gravitational outflow from the conical discharge hopper hole basing on results of research.

\section{Main Material Presentation}

In practice, the following two forms of the discharge hole are most often used: the conical (Fig. 1, a) and wedge-shaped symmetric (Fig. 1, b) and asymmetric (Fig. 1, c) with the outlet of the rectangular section and with the ratio of its lengths $l_{o}: b_{o}>3$ [2]. The partial variant of the asymmetric wedge-shaped well is the lower part of the conical hole with a shut-off conical bottom in the outlet.

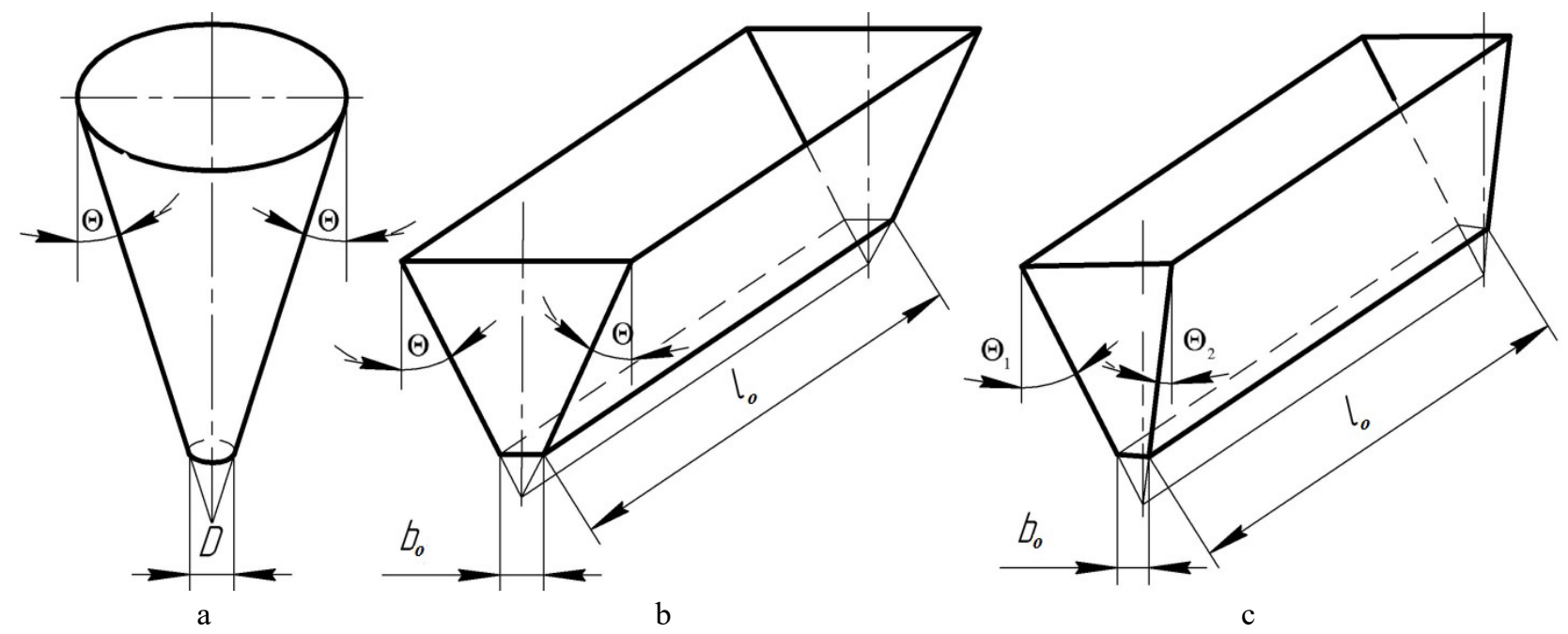

Fig. 1. Typical forms of discharge hoppers of the dispenser: $a$ - conical; b - symmetrical wedge-shaped; $\mathrm{c}$ - asymmetric wedge-shaped 


\section{Yurii Sholovii, Nadiia Maherus}

In order to determine the geometric parameters of the discharge hopper hole, a mathematical model based on the analysis of the BM behavior with its gravitational outflow was developed. The following assumptions [3] were used to simulate the gravitational outflow of BM: 1) the elementary volume of the product considered during the simulation was significantly larger than the size of the particles forming it (the linear dimensions of the elementary volume of the product were to be at least 25 times larger than the size of the BM particles); 2) the interaction of the particles was considered to be absolutely flexible (neglected by any deformation or their erasure); 3) between the particles of the material there acts the autohesion force, which characterized the product cohesion.

The development of the behavioural model of finely dispersed BM in the discharge hopper hole was based on the study of force factors, which cause the formation of a stable dome above the outlet. The product, which was in the elementary volume of the dome, was affected by the proper force increments which values are determined by the shape and size of the discharge hole [4]. At first, the gravitational outflow of a fine-dispersed BM from the conical discharge hopper hole (Fig. 2) was considered.

Having used one of the methods of studying the behaviour of BM, namely the analysis of the tense state of a real product layer, the force balance equation acting on the elementary volume of the dome [5] was composed. For a conical discharge hopper hole (Fig. 2) in the projection on the vertical axis, it is of the following form:

$$
d F_{\text {aut }}+d F_{C}=d G
$$

where $d F_{\text {aut }}$ is autohesion force gain; $d F_{C}$ is outflow counter-force gain; $d G$ is gravity force gain.

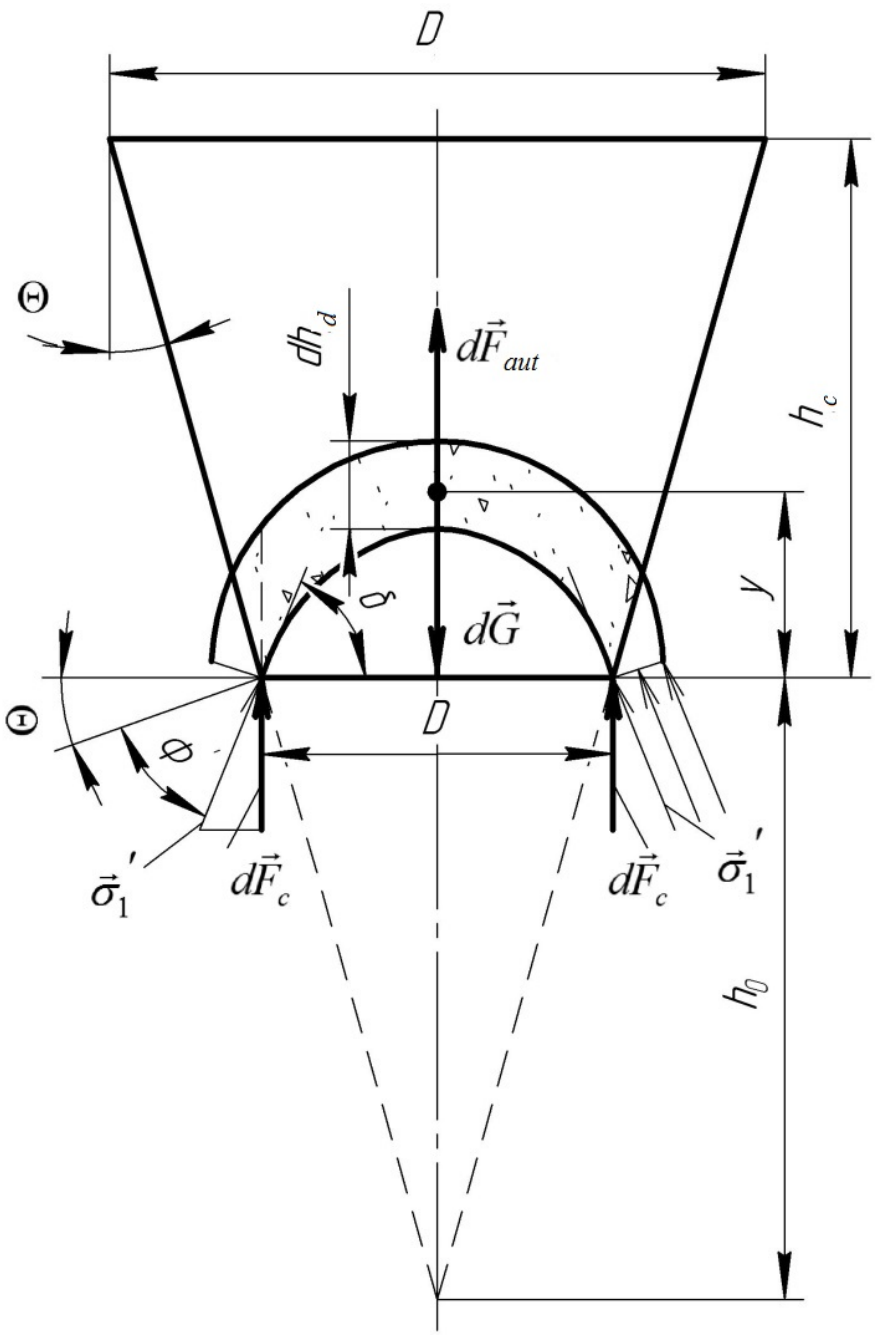

Fig. 2. The scheme of the forces acting on the elementary volume of the dome, with gravitational outflow of finely dispersed BM from the conical discharge hopper hole 


\section{Substantiation of Geometric Parameters of Discharge Hopper Hole at Gravitational Outflow ...}

To simulate the BM behaviour in a conical discharge hopper hole, all force factors acting on the elevated elementary volume of the dome of height $d h_{d}$ (Fig. 2) have been investigated. The driving force of free gravitational outflow is gravity force, as it is precisely in the absence of additional disturbances stimulates the outflow of product through the outlet. The gravity force gain has been determined by the dependence [5]:

$$
d G=\rho_{0} \cdot g \cdot d h_{d} \cdot S_{h},
$$

where $\rho_{0}$ is the bulk density of finely dispersed BM; $g$ is acceleration of the gravity force; $S_{h}$ is the area of the horizontal section of the elementary volume of the dome in the conical discharge hopper hole.

The area of the horizontal section of the elementary volume of the dome in the conical hole (fig. 2) has been approximately determined by the dependence:

$$
S_{h}=\pi \cdot \frac{D^{2}}{4},
$$

where $D$ is the diameter of the outlet of the discharge hopper hole.

Then the equation (2) taking into account the dependence (3) will be of the form:

$$
d G=\frac{\rho_{0} \cdot g \cdot d h_{d} \cdot \pi \cdot D^{2}}{4} .
$$

The presence of moisture in the fine-dispersed BM affects its bulk density [7]:

$$
\rho_{0}=\frac{\rho_{d} \cdot\left(1+W_{a b s}\right)}{1+\frac{W_{a b s} \cdot \rho_{m}}{3 \cdot \rho_{w}}},
$$

where $\rho_{d}$ is the bulk density of dry $\mathrm{BM} ; \rho_{m}$ is the density of BM particles; $\rho_{w}$ is water density; $W_{a b s}$ is absolute moisture.

Significant importance in the flow of finely dispersed BM from the capacities has the autohesion force, that is, the adhesive action between the particles of the product [6]. To ensure normal outflow, the degree of the product sealing must not exceed the critical value. The adhesive action between BM particles in the hopper depends on its size and configuration, as well as the properties of the dosage product [7].

The autohesion force gain is determined by the dependence [1]:

$$
d F_{\text {aut }}=\frac{d F_{\tau 0}}{f},
$$

where $d F_{\tau 0}=\tau_{0} \cdot S_{v}$ is increment of tearaway force; $\tau_{0}$ is the initial resistance of the shift of BM under the action of the tangent load; $S_{v}$ is area of the vertical section of the elementary volume of the dome; $f=\tan (\Phi)$ is internal-friction coefficient of BM; $\Phi$ is the angle of internal friction of BM.

The area of the vertical section of the elementary volume of the dome in the conical discharge hopper hole (Fig. 2) has been determined by the dependence:

$$
S_{v}=d h_{d} \cdot l_{d},
$$

where $l_{d}=\frac{\delta \cdot D}{\sin (\delta)}$ is the length of the arc of the dome; $\delta=\Theta+\Phi^{\prime} ; \Theta$ is angle of inclination of the walls

of the hole to the vertical; $\Phi^{\prime}$ is the angle of friction of BM to the wall of the discharge hopper hole.

Substituting the expression (7) in the equation (6), we have obtained the significance of the growth of the autohesion force for the conical discharge hopper hole:

$$
d F_{\text {aut }}=\frac{\tau_{0} \cdot d h_{d} \cdot \delta \cdot D}{f \cdot \sin (\delta)} .
$$

Significant resistance to the displacement of product particles in the discharge hole is performed by the counter-force of the outflow, the increase of which is determined by the formula [8]: 


\section{Yurii Sholovii, Nadiia Maherus}

$$
d F_{C}=\sigma_{1}^{\prime} \cdot \sin (\delta) \cdot d h_{d} \cdot \cos (\delta) \cdot P,
$$

where $\sigma_{1}^{\prime}$ is strain of free flow; $P$ is perimeter of the outlet hole of the hopper hole.

For a conic hole, taking into account that $P=\pi \cdot D$, the counter-force gain of the flow equals to:

$$
d F_{C}=\sigma_{1}^{\prime} \cdot \sin (\delta) \cdot d h_{d} \cdot \cos (\delta) \cdot \pi \cdot D
$$

Using the expressions to determine all the increments of the forces (4), (8), (10), acting on the elementary volume of the dome in the conical discharge hopper hole, and substituting them into the force balance equation (1), we have obtained:

$$
\frac{\tau_{0} \cdot d h_{d} \cdot \delta \cdot D}{f \cdot \sin (\delta)}+\sigma_{1}{ }^{\prime} \cdot \sin (\delta) \cdot d h_{d} \cdot \cos (\delta) \cdot \pi \cdot D=\frac{\rho_{0} \cdot g \cdot d h_{d} \cdot \pi \cdot D^{2}}{4} .
$$

From the equation of equilibrium of forces (11), the maximum diameter $D$ of the outlet of the hopper hole has been determined, which implements the effect of "self-locking" the flow of the product:

$$
D=\frac{4 \cdot\left(\tau_{0} \cdot \delta+0,5 \cdot \sigma_{1}^{\prime} \cdot \sin (2 \delta) \cdot \sin (\delta) \cdot \pi \cdot f\right)}{f \cdot \sin (\delta) \cdot \rho_{0} \cdot g \cdot \pi} .
$$

For further study of the geometric parameters of the discharge hopper holes it is important to establish the magnitude of the free-flow flux of BM [9]:

$$
\sigma_{1}^{\prime}=\frac{\sigma_{h 0}}{\left(m_{f}+1\right) \cdot \frac{Y^{*} \cdot(1+\sin (\Phi))}{2\left(X^{*}-1\right) \cdot \sin (\Theta) \cdot F^{*}}},
$$

where $\sigma_{h 0}$ is the axial tension of the BM in the discharge hole; $m_{f}$ is the coefficient of the form ( $m_{f}=1$ - for the conical hole, $m_{f}=0$ - for the wedge-shaped hole (or conical with the ring outlet), $X^{*}, Y^{*}, F^{*}$ are the coefficients determined by the corresponding dependences [9]:

$$
\begin{gathered}
X^{*}=\frac{2^{m_{f}} \cdot \sin (\Phi)}{1-\sin (\Phi)} \cdot\left(\frac{\sin \left(2 \beta^{*}+\Theta\right)}{\sin (\Theta)}+1\right), \\
Y^{*}=\frac{\left(2 \cdot\left(1-\cos \left(\beta^{*}+\Theta\right)\right)\right)^{m_{f}} \cdot\left(\beta^{*}+\Theta\right)^{1-m_{f}} \sin (\Theta)+\sin \left(\beta^{*}\right) \cdot\left(\sin \left(\beta^{*}+\Theta\right)\right)^{1+m_{f}}}{(1-\sin (\Phi)) \cdot\left(\sin \left(\beta^{*}+\Theta\right)\right)^{2+m_{f}}}, \\
F^{*}=\left(\frac{130^{\circ}}{130^{\circ}+\Theta}\right)^{m_{f}} \cdot\left(\frac{200^{\circ}}{200^{\circ}+\Theta}\right)^{1-m_{f}}, \\
\beta^{*}=\frac{1}{2}\left(\Phi^{\prime}+a \sin \left(\frac{\sin \left(\Phi^{\prime}\right)}{\sin (\Phi)}\right)\right)
\end{gathered}
$$

Having used the hypothesis about the boundary product balance in a highlighted elementary volume $d h_{d}$, the axial tension of the BM is of the form [5]:

$$
\sigma_{h 0}=\sigma_{l 0} \cdot\left(1+2 f^{2}-\sqrt{\left(1+2 f^{2}\right)^{2}-1-4 f_{w}{ }^{2} \cdot\left(1+f^{2}\right)}\right),
$$

where $\sigma_{l 0}$ is the radial stress of BM in its passive stress state; $f_{w}=\tan \left(\Phi^{\prime}\right)$ is the coefficient of friction of BM to the wall of the discharge hopper hole.

The radial stress of BM in a passive stress state has been determined by the dependence [5]: 
Substantiation of Geometric Parameters of Discharge Hopper Hole at Gravitational Outflow ...

$$
\sigma_{l 0}=\frac{\rho_{0} g\left(h_{0}+y\right)}{C_{n}\left(a_{n}-1\right)}\left(1-\left(\frac{h_{0}+y}{h_{0}+h_{c}}\right)^{a_{n}-1}\right)+\sigma_{l 0} H \cdot\left(\frac{h_{0}+y}{h_{0}+h_{c}}\right)^{a_{n}},
$$

where $h_{0}$ is the distance from the outlet of the discharge hopper hole to the imaginary top of the cone (Fig. 2); $y$ is the current vertical coordinate of the place of formation of a stable dome; $h_{c}$ is the height of the hole; $\sigma_{l 0}{ }^{H}$ is the radial stress of BM on the upper edge of the hopper hole; $C_{n}, a_{n}$ are coefficients.

The coefficients $C_{n}$ and $a_{n}$ for the passive stressed state of the BM, which is typical for the formation of the dome, are of the form [5]:

$$
\begin{gathered}
C_{n}=1+2 f^{2}-\frac{\sqrt{\left[\left(1+2 f^{2}\right)^{2}-1\right]^{3}-\sqrt{\left[\left(1+2 f^{2}\right)^{2}-1-4 f_{w}^{2}\left(1+f^{2}\right)\right]^{3}}}}{6 f_{w}\left(1+f^{2}\right)}, \\
a_{n}=\frac{2 \cos (\Theta)\left(f_{w}+\sin (\Theta)\right)}{C_{n} \cdot \tan (\Theta)} .
\end{gathered}
$$

When determining the optimal parameters of the discharge hopper hole, both its geometry and the properties of the loaded finely dispersed BM are important. To simulate the behaviour of finely dispersed $\mathrm{BM}$ in a gravitational outflow, wheat flour with properties was selected [5]: $\left(\Phi=42^{\circ} ; \Phi^{\prime}=30^{\circ}\right.$; $\left.\rho_{0}=0,5 \cdot 10^{3} \mathrm{~kg} / \mathrm{m}^{3}\right)$, as well as the following values are necessary for the simulation of the indicators: $\sigma_{l 0}{ }^{H}=0 ; h_{0}+y=0.25 \mathrm{~m} ; h_{0}+h_{c}=0.45 \mathrm{~m} ; l_{1}=l_{2}=0.5 \mathrm{~m}$ - have been constructively established. The initial resistance of the shift of wheat flour under the action of the tangent load varies within $\tau_{0}=50 \ldots 150 \mathrm{~Pa}[5]$.

In addition to the required diameter of the outlet $D$, when constructing the hopper hole, it is often necessary to determine the angle of its walls $\Theta$. Having used the formula (12) - (17), the graphical dependencies $D(\Theta)$ have been obtained in the MathCAD software environment (Fig. 3).

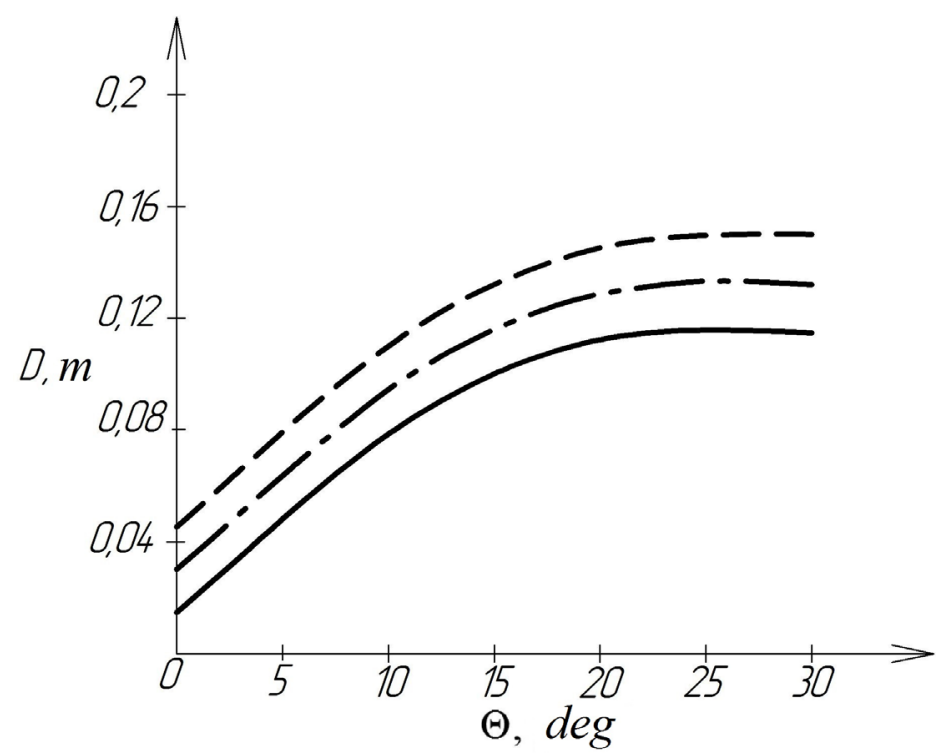

Fig. 3. The dependence of the size of the outlet of the conical discharge hopper hole on its angle of inclination:

$$
\left(\text { ( }^{- \text {for }} \tau_{0}=50 \mathrm{~Pa} ;-Z_{-} \text {for } \tau_{0}=100 \mathrm{~Pa} ;-_{-} \text {- for } \tau_{0}=150 \mathrm{~Pa}\right)
$$

As the inclination angle of the walls of the conical discharge hopper hole $\Theta$ increases, the outer diameter of the outlet $D$ is increased (Fig. 3), at which it is possible to form a stable dome above the 


\section{Yurii Sholovii, Nadiia Maherus}

outlet. Significant influence on the geometric dimensions of the well has the product cohesion, which characterizes the autohesion force. It has been established that with the conditional diameter of the particles of the material $d \leq 100 \mu \mathrm{m}$, the autohesion force may be greater or equal to gravity [1], and therefore its non-consideration in the study of the behaviour of finely dispersed BM leads to lowering of the extremal diameter of the outlet of the conical hopper hole $D$. With a small initial resistance of the BM displacement $\tau_{0}=50 \mathrm{~Pa}$, limiting value of the diameter of the outlet is within $0,04<D<0,13 \mathrm{~m}$ for $0^{\circ}<\Theta<30^{\circ}$ (Fig. 3). With the increase of the initial displacement resistance of the dispensing product $\tau_{0}=100 \mathrm{~Pa}$, the maximum diameter of the outlet, which will ensure the formation of a stable dome of the $\mathrm{BM}$ over the outlet in the same range of angle change of the inclination of the walls of the discharge hole $\Theta$, is within the limits of $0,07<D<0,16 \mathrm{~m}$, and, accordingly, for $\tau_{0}=150 \mathrm{~Pa}$ its maximum value $\Theta=30^{\circ}$ increases to $D \approx 0,22 \mathrm{~m}$. The graphic dependencies (Fig. 3) shown here allow us to assert that the increase in the angle of inclination of the unloading well of the dispenser from $0^{\circ}$ to $30^{\circ}$ allow you to increase the diameter of the outlet $D$ in the range of $50 \%$, which significantly affects both the productivity and the dimensions of the hopper.

On the basis of the graphic dependencies obtained (Fig. 3), we can make the following conclusions:

1. The increasing nature of the curves is explained by the fact that with increasing the angle of the wall slopes of the discharge hopper hole, the value of the bulk density of the BM in the outlet area increases, which leads to increased adhesion between the particles of the product. Therefore, the limiting size of the outlet of the hole, which ensures the absence of gravitational outflow of finely dispersed BM, is also increasing.

2. The intensity of the curves growth is much larger at the angle of the wall of the discharge hole $\Theta \leq 20^{\circ}$. This is due to the significant sealing of the material in the outlet area, which reaches its critical value for the product under investigation with $\Theta \approx 20^{\circ}$. Therefore, further increase of the angle of the walls slope $20^{\circ}<\Theta<\Theta_{\max }$ practically does not affect the change in the limit value of the diameter of the outlet $D$ of the conical discharge hopper hole.

The conditions for the continuous flow of product from the hopper also essentially depend on the material friction angle $\Phi^{\prime}$ to its working surfaces (Fig. 4). The coefficient of external friction of BM $f_{w}$ characterizes the resistance to the displacement of BM particles on the working surface of the discharge hole. Its size is influenced by the physical and mechanical properties of the product, the properties of the contact surfaces, the velocity of the BM and the contact time of the friction surfaces [5].

When setting dependencies $D\left(f_{w}\right)$ (Fig. 4), the following values required for simulation of the indicators were chosen: $\Phi=42^{\circ} ; \quad \tau_{0}=50 \mathrm{~Pa} ; \quad \sigma_{l 0}{ }^{H}=0 ; \quad h_{0}+y=0,25 \mathrm{~m} ; \quad h_{0}+h_{c}=0,45 \mathrm{~m}$; $l_{1}=l_{2}=0,5 \mathrm{~m}$. The angle of the conical discharge hole (Fig. 4) was assumed to be equal to $\Theta=25^{\circ}$. The bulk density of the $\mathrm{BM}$ varied widely, for example, it was $450<\rho_{0}<700 \mathrm{~kg} / \mathrm{m}^{3}$ [5] for wheat flour, therefore for $D\left(f_{w}\right)$ was used to obtain dependencies $\rho_{0}=500 \mathrm{~kg} / \mathrm{m}^{3}$ and $\rho_{0}=700 \mathrm{~kg} / \mathrm{m}^{3}$.

From the graphic dependencies (Fig. 4), it follows that the growth of the coefficient of external friction of $\mathrm{BM} f_{w}$ to the walls of the discharge hopper hole allows to increase the limiting value of the diameter of the outlet $D$ of the conical hole. However, an increase in the bulk density $\rho_{0}$ of the product (in the same way as all other physical and mechanical characteristics) leads to improvement of the outflow conditions of BM in connection with its increase in weight. This, accordingly, affects the reduction of the limiting size of the outlet $D$ of the discharge hole.

At the bulk density $\rho_{0}=500 \mathrm{~kg} / \mathrm{m}^{3}$ in the range of the change in the coefficient of external friction of $\mathrm{BM} 0,3<f_{w}<0,6$, the maximum diameter of the outlet of the conical discharge hole changes in the 

range $0,05<D<0,07 \mathrm{~m}$ (Fig. 4). In the study of $\mathrm{BM}$ with a bulk density $\rho_{0}=700 \mathrm{~kg} / \mathrm{m}^{3}$, the above parameters are within: $0,08<D<0,1 \mathrm{~m}$.

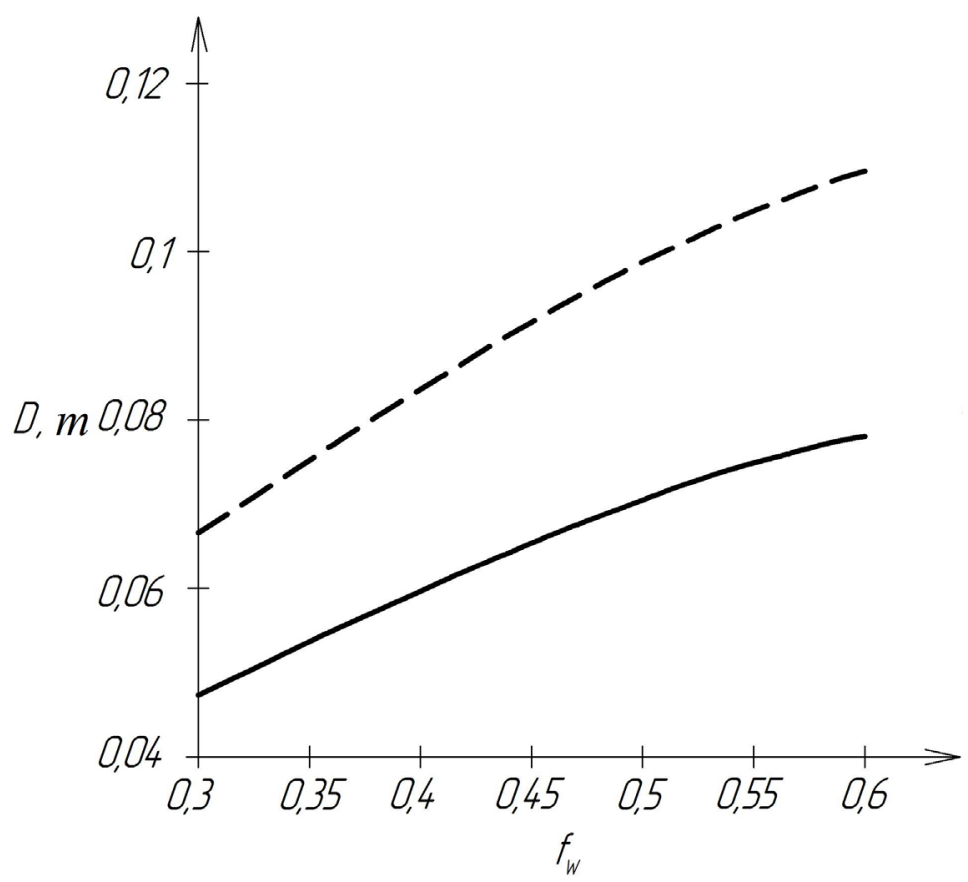

Fig. 4 The dependence of the size of the outlet of the conical discharge hopper hole on the coefficient of external friction ( $-{ }_{-}$for $\rho_{0}=500 \mathrm{~kg} / \mathrm{m}^{3} ;{ }_{-}-\rho_{0}=700 \mathrm{~kg} / \mathrm{m}^{3}$ )

Consequently, the analysis of graphic dependencies (Fig. 4) allows us to conclude that with the increase of the coefficient of external friction of BM to the walls of the discharge hole $f_{w}$, the limiting size of its outlet $D$, in which there is no gravitational outflow, increases. However, with $f_{w} \geq 0,5$, the intensity of growth of the curves $D\left(f_{w}\right)$ is significantly reduced, as the resistance to product displacement becomes so significant that the boundary layer of particles that come in contact with the walls of the discharge hole adheres to them, and slipping occurs only between the layers of the material.

The reduction of the coefficient of external friction of BM $f_{w}$ improves the outflow conditions of the product. The following antifriction coatings as chlororubber lacquer, epoxy resin, polyurethane, artificial rubber, etc., are used to reduce the friction angle of the material $\Phi^{\prime}$ to the working surfaces, as well as facing of the walls of the hoppers with plastic foil, plastic plates and glass tiles are used [10].

\section{Conclusions}

As e result, the main property of finely dispersed BM, which affects the performance of the hoppers, is flowability, which characterizes the movement of material in the area of the outlet. The freely poured, diluted product is saturated with air and does not resist outflow. If the material is loaded into a hopper or another container (where no lateral expansion is possible), the situation is very different. Under the pressure of the upper layers in the BM there is a stress, its porosity decreases, which leads to bulk density increase. Depending on the fraction of the material, the shape of the particles, the amount of moisture in the product pores and its degree of consolidation, the value of the bulk density for a particular material may deviate by $200-250 \%$ [2]. When the material is sealed, the air is displaced and the adhesion forces between the particles grow. As a result, the outflow of BM becomes complicated and a stable dome is formed over the outlet. Therefore, in order to ensure the efficient operation of the hoppers during its design, it is important to investigate the interdependence of the main geometric parameters of the discharge hole and the effect of the physical and mechanical properties of the BM. 


\section{Yurii Sholovii, Nadiia Maherus}

\section{References}

[1] A. D. Zimon, Autogezija sypuchih matierialov [Autohesion bulk materials]. Moscow, Russia: Himija Publ., 1978. [in Russian].

[2] E. V. Dzhenike, Skladirovanije i vypusk sypuchih matierialov [Warehousing and release of bulk materials]. Moscow, Russia: Mir Publ., 1968. [in Russian].

[3] Yu. P. Sholovij, and N. I. Prokopets, "Modeliuvannia povedinky dribnodyspersnogo materialu pry jogo vytikanni iz konichnoji lunky dozatora" ["Modeling the behavior of finely dispersed material when it flows from a conical well of the dispenser"], in Proc. 4th International Conference of Young Scientists EMT-2013, Lviv, Ukraine, November 21-23, 2013, pp. 42-43. [in Ukrainian].

[4] Yu. P. Sholovij, and N. I. Prokopets, "Obgruntuvannia konstruktyvnyh parametriv lunky dozatora dlia dribnodyspersnyh sypkyh materialiv" ["The substantiation of the design parameters of the hopper hole for finely dispersed bulk materials"], Avtomatyzatsija vyrobnychyh protsesiv u mashynobuduvanni ta pryladobuduvanni [Industrial Process Automation in Engineering and Instrumentation]. Lviv, Ukraine, 2013. - №47, pp. 45-50. [in Ukrainian].

[5] A. V. Katalymov, and V. A. Liubartovich, Dozirovanije sypuchih i viazkih materialov [Dosing of bulk and viscous materials]. Leningrad, Russia: Himija Publ., 1990. [in Russian].

[6] Yu. P. Sholovij, and N. I. Prokopets, "Osoblyvosti dozuvannia dribnodyspersnyh materialiv" ["Features of dosing of finely dispersed materials"], in Proc. 9th scientific-practical conference of young scientists "Novitni tehnologiji pakuvannia”, Kyiv, Ukraine, April 12, 2013, pp. 27-29. [in Ukrainian].

[7] Yu. I. Makarov, Apparaty dlia smeshenija sypuchih matierialov [Apparatus for mixing bulk materials], Moscow, Russia: Mashinostroenie Publ., 1973. [in Russian].

[8] G. Kache, "Verbesserung des Schwerkraftflusses kohäsiver Pulver durch Schwingungseintrag" ["Improvement of the gravity flow of cohesive powders due to vibration"], Dissertation, Otto-von-GuerickeUniversität Magdeburg, Magdeburg, Germany, 2009. [in German].

[9] G. Kache, and J. Tomas, "Ausfliessen eines kohäsiven, hochdispersen Pulvers" ["Outflow of a cohesive high-dispersed powder”], Schüttgut [Bulk Materials], no. 6, pp. 246-252, 2010. [in German].

[10] D. Schulze, Pulver und Schüttgüter. Fliesstigenschaften und Handhabung [Powder and bulk materials. Flow properties and handling]. Berlin, Germany: Springer, 2005. [in German].

[11] G. A. Roginskij, Dozirovanije sypuchih matierialov [Dosing of bulk materials]. Moscow, Russia: Himija Publ., 1978. [in Russian].

[12] T. Kollmann, "Schwingungsinduziertes Fließen feinstkörniger, kohäsiver Pulver" ["Vibration-induced flow of fine-grained cohesive powders"], Dissertation, Ottovon-Guericke-Universität Magdeburg, Magdeburg, Germany, 2002. 